\title{
Review
}

\section{Mutations Induced by Oxidized DNA Precursors and Their Prevention by Nucleotide Pool Sanitization Enzymes}

\author{
Hiroyuki Kamiya ${ }^{1}$ \\ Faculty of Pharmaceutical Sciences, Hokkaido University, Sapporo, Japan \\ (Received August 10, 2007; Revised September 1, 2007; Accepted September 4, 2007)
}

\begin{abstract}
Base oxidation occurs in the cellular nucleotide pool as well as in DNA, and the oxidized DNA precursors induce mutagenic events. 8-Hydroxy-dGTP (8-OH-dGTP) and 2 hydroxy-dATP (2-OH-dATP) have been identified as the major products of in vitro oxidation reactions with $\mathrm{Fe}^{2+}$. The mutagenic potentials of many oxidized DNA precursors have been examined in various experimental systems. Accumulating evidence indicates the importance of 8-OHdGTP and 2-OH-dATP in the mutation process. In addition, nucleotide pool sanitization enzymes, such as MutT and MTH1, have been identified as a defense against the mutagenesis induced by these oxidized DNA precursors. In this review, the mutagenicities of 8-OH-dGTP and 2-OH-dATP and the functions of MutT-type nucleotide pool sanitization enzymes will be summarized.
\end{abstract}

Key words: oxidized DNA precursor, 8-hydroxy-dGTP, 2 hydroxy-dATP, nucleotide pool sanitization enzyme

\section{Introduction}

Reactive oxygen species (ROS) are produced endogenously through normal cellular metabolism, and exogenously by various environmental mutagens and dietary factors (1-4). Various kinds of DNA lesions are generated by ROS, and the mutational properties of many DNA lesions have been examined (5). The formation of DNA lesions is recognized as being related to mutagenesis, carcinogenesis, neurodegeneration, and aging $(1,2,6)$.

Base oxidation occurs in the cellular nucleotide pool as well as in DNA, and the oxidized deoxyribonucleotides (DNA precursors) induce mutagenic events $(5,7)$. Previously, the in vitro oxidation products of dATP and dGTP were analyzed, and the amounts of oxidatively damaged bases were quantitated. DNA precursors were more susceptible to the oxidation than DNA. The amount of 8-hydroxyguanine (8-OH-Gua) formed upon the treatment of dGTP with $\mathrm{Fe}^{2+}$-EDTA is $\sim 9$-fold more abundant than that in DNA with the same treatment (8). Likewise, 2-hydroxyadenine (2-OH-Ade) is formed $\sim 67$-fold more efficiently upon dATP oxidation than upon DNA oxidation. Intracellular DNA is bound with proteins, such as histones, and its reactivity would be low, due to the protection by the proteins. Thus, the oxidation of DNA precursors in cells may play more important roles in ROS-induced mutagenesis than previously speculated. The accumulation of $8-\mathrm{OH}-\mathrm{Gua}$ by the incorporation of oxidized dGTP from the nucleotide pool contributes almost equally to the direct oxidation of G bases in DNA (9). Nunoshiba et al. reported that the mutations found in an Escherichia coli strain lacking superoxide dismutases and a repressor for iron-uptake systems were $\mathrm{A}: \mathrm{T} \rightarrow \mathrm{C}: \mathrm{G}$ and $\mathrm{G}: \mathrm{C} \rightarrow \mathrm{T}: \mathrm{A}$ transversions, and concluded that these mutations would be caused by 8-hydroxy-2'-deoxyguanosine 5'-triphosphate $(8-\mathrm{OH}$ dGTP) and 2-hydroxy-2'-deoxyadenosine 5'-triphosphate (2-OH-dATP), respectively, on the basis of various experiments (10). These results suggest that oxidatively damaged DNA precursors are biologically quite important.

Experiments with synthetic deoxyribonucleoside triphosphates provide clear data on the relationship between the damaged structures and the mutational properties. In this review, the author will particularly focus on 8-OH-dGTP and 2-OH-dATP (Fig. 1), which are the major products of in vitro oxidation reactions with $\mathrm{Fe}^{2+}$ (11). In addition, the nucleotide pool sanitization enzymes that function as a defense against the mutagenesis induced by oxidatively damaged DNA precursors will be discussed.

\section{Incorporation by Purified DNA Polymerases}

The incorporation of 8-OH-dGTP by various purified DNA polymerases (pols) has been examined in vitro, using synthetic oligodeoxyribonucleotides as primed templates. The oxidized form of dGTP is incorporated opposite $\mathrm{C}$ and $\mathrm{A}$ in the templates (Table 1). The ratio of the incorporation of 8-OH-dGTP opposite A to that opposite $\mathrm{C}$ varies, depending upon the DNA pol (12-16).

${ }^{1}$ Correspondence to: Hiroyuki Kamiya, Faculty of Pharmaceutical Sciences, Hokkaido University, Kita-12, Nishi-6, Kita-ku, Sapporo 060-0812, Japan. Tel: +81-11-706-3733, Fax: +81-11-706-4879, E-mail: hirokam@pharm.hokudai.ac.jp 

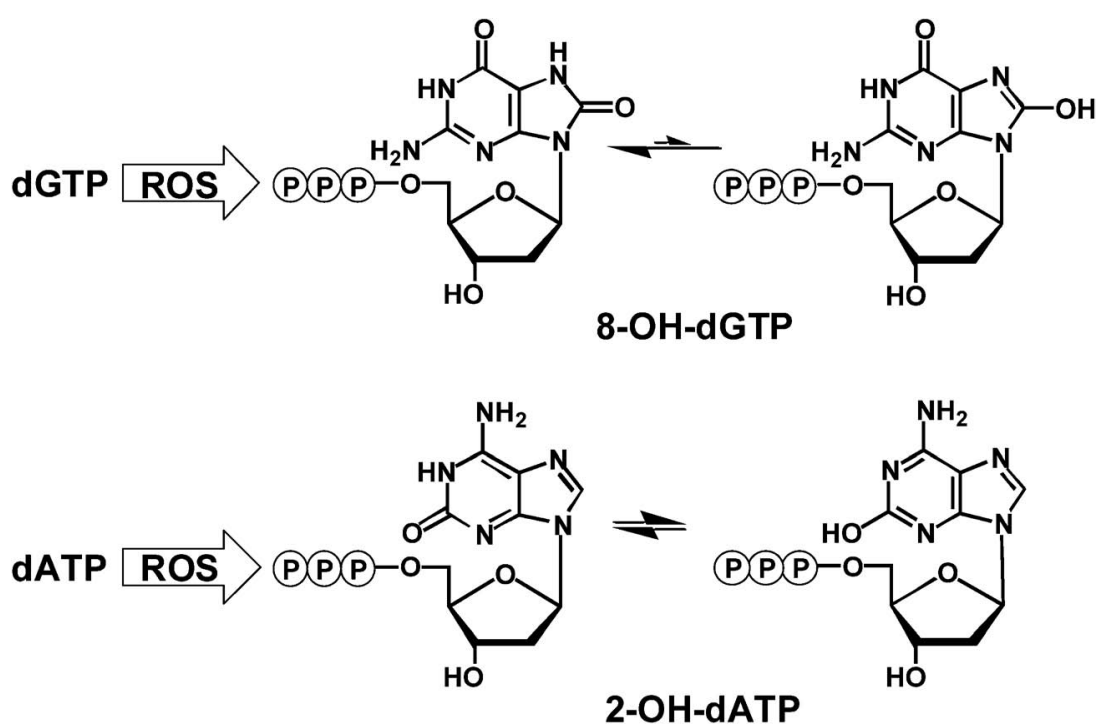

Fig. 1. Structures of 8-OH-dGTP and 2-OH-dATP. The equilibrium between the keto (left) and hydroxy (right) forms shifts to the keto form for 8 -OH-dGTP. The proportion of the two forms of 2-OH-dATP is affected by the environment around the compound (60,61). (P represents a phosphate group.

Table 1. Mutations induced by $8-\mathrm{OH}-\mathrm{dGTP}$ and 2-OH-dATP in various experimental systems

\begin{tabular}{llcc}
\hline \hline \multirow{2}{*}{ DNA precursors } & \multicolumn{2}{c}{ Experimental system } & \\
\cline { 2 - 4 } & Purified DNA pol & E. coli & Human cell extract \\
\hline 8-OH-dGTP & Misincorporation opposite A & A:T $\rightarrow$ C:G $\rightarrow$ C:G \\
2-OH-dATP & Misincorporation opposite C and G & G:C $\rightarrow$ T:A & G:C $\rightarrow$ A:T \\
& & & G:C $\rightarrow$ T:A \\
\hline
\end{tabular}

Shimizu et al. have reported that the Y-family DNA pols, including Sulfolobus acidocaldarius DNA pol Y1 (Dbh), S. solfataricus strain P2 DNA pol Y1 (Dpo4), $E$. coli DNA pol IV (DinB), human DNA pol $\eta$ (XPV), and pol $l$, incorporate $8-\mathrm{OH}$-dGTP opposite A with quite high frequencies (17-19). 8-OH-dGTP was added to the deoxyribonucleotides used for the gap-filling reaction by the Klenow fragment of $E$. coli DNA pol I, and the synthesized DNA was transfected into E. coli (20). A $\rightarrow$ C transversions were almost exclusively detected. Similar results were obtained when other DNA pols, including the $E$. coli DNA pol III holoenzyme, were used $(21,22)$. The $\mathrm{A} \rightarrow \mathrm{C}$ transversions observed in these studies imply that $8-\mathrm{OH}-\mathrm{dGTP}$ is incorporated opposite $\mathrm{A}$, and then dCTP is inserted opposite 8-OH-Gua in the DNA (Fig. 2).

The incorporation of 2-OH-dATP by purified DNA pols in vitro has also been examined, using synthetic oligodeoxyribonucleotides as primed templates (Table $1)$. The E. coli DNA pol III $\alpha$ subunit incorporates 2 $\mathrm{OH}$-dATP opposite $\mathrm{T}$ and $\mathrm{G}$ (23). The kinetic parameters of the incorporation indicated that the efficiencies opposite $T$ and $G$ are $\sim 10: 1$. On the other hand, the mammalian replicative DNA pol, pol $\alpha$, incorporates 2-

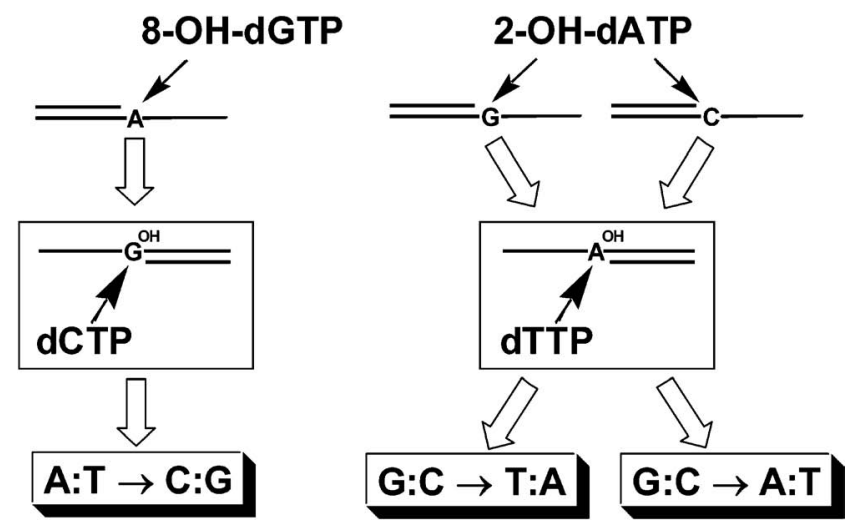

Fig. 2. Proposed model for mutations induced by $8-\mathrm{OH}-\mathrm{dGTP}$ and 2-OH-dATP. 2-OH-dATP is misincorporated opposite $\mathrm{G}$ and $\mathrm{C}$ in a DNA pol-dependent manner. $\mathrm{G}^{\mathrm{OH}}, 8-\mathrm{OH}-\mathrm{Gua}$; $\mathrm{A}^{\mathrm{OH}}$, 2-OH-Ade.

OH-dATP opposite $\mathrm{T}$ and $\mathrm{C}$ with $\sim 4.5: 1$ efficiencies (8). In contrast to 8-OH-dGTP, the incorporation mode of 2-OH-dATP is DNA pol-dependent. Interestingly, the DNA pol-dependency is observed for mispair formation of 2-OH-Ade in DNA templates $(24,25)$. Shimizu et al. reported that the incorporation of 2-OHdATP opposite $\mathrm{T}$ and $\mathrm{G}$ occurs with similar efficiencies 
by the Y-family DNA pols (17-19). The gap-filling reaction by the $E$. coli DNA pol III holoenzyme was examined, and $\mathrm{G} \rightarrow \mathrm{T}$ transversions were found to be induced (22). It seems that 2-OH-dATP is incorporated opposite $\mathrm{G}$, and then dTTP is inserted opposite 2-OH-Ade in the DNA (Fig. 2).

The misincorporation of other damaged DNA precursors has been studied using various purified DNA pols, as described in detail in another review (5).

\section{Mutations Induced in $E$. coli}

The mutagenicity of 8-OH-dGTP and 2-OH-dATP in vivo was examined by the direct incorporation of damaged DNA precursors, by treating $E$. coli cells with $\mathrm{CaCl}_{2}$ and isolating the mutants of a target gene (26). The treatments with 8-OH-dGTP and 2-OH-dATP increased the frequency of substitution mutations, in contrast to the treatments with dGTP and dATP. This result indicates that damaged DNA precursors act as mutagens in cells. The substitution mutation found most frequently in the 8-OH-dGTP-induced mutants is an $\mathrm{A}: \mathrm{T} \rightarrow \mathrm{C}: \mathrm{G}$ transversion (Table 1). This type of mutation comprised $90 \%$ of the substitution mutations detected, in the case of the lacI gene (26). The substitution mutation found most frequently in the 2-OH-dATP-induced mutants was a $\mathrm{G}: \mathrm{C} \rightarrow \mathrm{T}: \mathrm{A}$ transversion $(84 \%$ of the total substitution mutations detected in the lacI gene). As described in the Introduction section, Nunoshiba et al. reported that the mutations found in an $E$. coli strain lacking superoxide dismutases and a repressor for iron-uptake systems were $A: T \rightarrow C: G$ and $\mathrm{G}: \mathrm{C} \rightarrow \mathrm{T}: \mathrm{A}$ transversions, and concluded that these mutations would be caused by $8-\mathrm{OH}-\mathrm{dGTP}$ and $2-\mathrm{OH}-$ dATP, respectively (10). Thus, these results suggest that the 8-OH-dGTP and 2-OH-dATP formed in the nucleotide pool contribute to the mutations induced by ROS. The A:T $\rightarrow \mathrm{C}: \mathrm{G}$ and $\mathrm{G}: \mathrm{C} \rightarrow \mathrm{T}: \mathrm{A}$ transversions observed for $8-\mathrm{OH}-\mathrm{dGTP}$ and 2-OH-dATP, respectively, would be initiated by their misincorporations opposite $\mathrm{A}$ and G (Fig. 2).

When 5-hydroxy-2'-deoxycytidine 5'-triphosphate and 5-formyl-2'-deoxyuridine 5'-triphosphate, oxidized dCTP and dTTP, respectively, were introduced directly into $E$. coli, these deoxyribonucleotides induced $\mathrm{lacI}^{-}$ and $\mathrm{lacO}^{\mathrm{c}}$ mutants as efficiently as 8-OH-dGTP (27). 5Hydroxy-2'-deoxycytidine 5'-triphosphate and 5-formyl-2'-deoxyuridine 5'-triphosphate induced $\mathrm{A}: \mathrm{T} \rightarrow$ $\mathrm{C}: \mathrm{G}, \mathrm{A}: \mathrm{T} \rightarrow \mathrm{G}: \mathrm{C}$, and $\mathrm{G}: \mathrm{C} \rightarrow \mathrm{T}: \mathrm{A}$ mutations, and $\mathrm{G}: \mathrm{C} \rightarrow$ $\mathrm{A}: \mathrm{T}, \mathrm{A}: \mathrm{T} \rightarrow \mathrm{G}: \mathrm{C}$, and $\mathrm{G}: \mathrm{C} \rightarrow \mathrm{T}: \mathrm{A}$ mutations, respectively. In contrast, 8-hydroxy-2'-deoxyadenosine 5'triphosphate (8-OH-dATP), which is formed by ionizing radiation, caused little, if any, mutagenesis (28). The mutagenicity of $8-\mathrm{OH}-\mathrm{dATP}$ is at least one order of magnitude lower than that of 2-OH-dATP in E. coli. In addition, formamidopyrimidine-dGTP (Fapy-dGTP,
$N^{6}$ - (2 - deoxy - $\alpha, \beta$ - D - ribofuranosyl) - 2, 6 - diamino - 5 formamido-4-hydroxypyrimidine 5 '-triphosphate), another oxidation product of dGTP, is nonmutagenic in $E$. coli (Kamiya et al., unpublished results).

\section{Mutations Induced in in vitro DNA Replication with Extracts of Human Cells}

The effects of 8-OH-dGTP on the fidelity of replication conducted by a HeLa cell extract have been reported (Table 1) (21). The replicated DNA was transfected into $E$. coli, and $\mathrm{A}: \mathrm{T} \rightarrow \mathrm{C}: \mathrm{G}$ mutations were induced. This induction of $\mathrm{A}: \mathrm{T} \rightarrow \mathrm{C}: \mathrm{G}$ mutations by $8-\mathrm{OH}-\mathrm{dGTP}$ was dependent on the MutY activity: The frequency of these mutations decreased when mut $Y$ strains were used as host cells (21). The mutagenicity of 2-OH-dATP was also examined, using an in vitro replication system with a HeLa extract. 2-OH-dATP induced substitution and deletion mutations (29). Among the substitutions, a $\mathrm{G}: \mathrm{C} \rightarrow \mathrm{A}: \mathrm{T}$ transition including a tandem $(\mathrm{CC} \rightarrow \mathrm{TT}) \mathrm{mu}-$ tation was mainly induced. This result is in contrast to the finding that $\mathrm{G}: \mathrm{C} \rightarrow \mathrm{T}: \mathrm{A}$ transversions are induced by 2-OH-dATP in E. coli cells (Table 1). This discrepancy can be explained by the DNA pol-dependent misincorporation mode of 2-OH-dATP $(8,23)$, which is incorporated opposite $\mathrm{C}$ in the extract, as by purified DNA pol $\alpha$ (Fig. 2).

Recently, we observed that 2-OH-dATP synergistically enhanced the mutagenicity of $8-\mathrm{OH}-\mathrm{dGTP}$ in the reaction (30). 2-OH-dATP suppressed the hydrolysis of 8-OH-dGTP, suggesting that the inhibition of an MTH1(-like) protein played a major role in the enhancement (see below). These results highlight the importance of the specific hydrolysis of 8-OH-dGTP for the suppression of its induced mutation.

\section{Mutations Induced in Live Mammalian Cells}

To examine the mutagenicity of 8-OH-dGTP in mammalian cells, 8-OH-dGTP and shuttle plasmid DNA containing a target gene were co-introduced by means of cationic liposomes into simian COS-7 cells. The DNAs replicated in the cells were recovered and then transfected into E. coli. The 8-OH-dGTP induced A:T $\rightarrow \mathrm{C}: \mathrm{G}$ substitution mutations in the COS-7 cells (31). This result agrees with previous observations that DNA pols misincorporated 8-OH-dGTP opposite A in vitro, and that this oxidized dGTP induced $\mathrm{A}: \mathrm{T} \rightarrow \mathrm{C}: \mathrm{G}$ transversions in E. coli. As described above, the observed $A: T \rightarrow C: G$ transversions observed can be explained by the incorporation of 8-OH-dGTP opposite A and the insertion of dCTP opposite 8-OH-Gua in DNA during the next round of replication (Fig. 2). These results constitute the first direct evidence to show that 8-OH-dGTP actually induces mutations in living mammalian cells. 


\section{Roles of Y-family DNA Polymerases in Mutation Induction}

As described above, some Y-family DNA pols incorporate damaged DNA precursors opposite incorrect bases with high frequencies in vitro (17-19). To reveal the roles of Y-family DNA pols in the mutagenesis induced by oxidatively damaged DNA precursors, $2-\mathrm{OH}-$ dATP and 8-OH-dGTP were introduced into E. coli strains deficient in the Y-family DNA pols, DNA pol IV (DinB) and DNA pol V (UmuD' $\left.{ }_{2} \mathrm{C}\right)(32)$. The mutation induced by $2-\mathrm{OH}-\mathrm{dATP}$, but not that induced by $8-\mathrm{OH}-$ dGTP, occured less frequently in the $\operatorname{din} B$ strain than in the wild-type (wt) strain, suggesting the involvement of DNA pol IV in the mutagenesis by 2-OH-dATP. The expression of DNA pol IV from a plasmid enhanced the mutagenesis by 2-OH-dATP in the $\operatorname{din} B$ strain. This enhancement was dependent on the DNA pol activity, since the expression of a mutant DNA pol IV lacking the pol activity did not increase the mutations induced by 2 OH-dATP. As revealed by the in vitro DNA synthesis experiment (18), DNA pol IV seems to facilitate the mutagenicity of 2-OH-dATP through the misincorporation of 2-OH-dATP. Moreover, DNA pol IV may be involved in the extension from the 3'-terminal 2-OH-Ade residue. Alternatively, DNA pol IV may function in the fixation of mutations, by the incorporation of dTTP opposite 2-OH-Ade during the second round of replication and/or the extension from the 3'-terminal $T$ residue incorporated opposite 2-OH-Ade (Fig. 2). In contrast, both 8-OH-dGTP and 2-OH-dATP caused mutations more efficiently in the $u m u D C$ strain than in the wt strain, suggesting that the $u m u D C$ gene products suppressed the mutagenesis by these oxidized DNA precursors (32). The DNA pol activity was not required for the suppressive effects, since the expression of the $u m u D C$ gene products lacking the DNA pol activity also suppressed the mutagenesis. These results suggest that $E$. coli DNA pol IV is involved in the mutagenesis by 2 $\mathrm{OH}-\mathrm{dATP}$, and that the $u m u D C$ gene products play suppressive role(s) in the mutagenesis by both $8-\mathrm{OH}$ dGTP and 2-OH-dATP.

The mutagenicity of 8-OH-dGTP in an in vitro replication system with an extract of XP-V cells lacking a Yfamily DNA pol, pol $\eta$, was similar to that with a HeLa extract (30). This result suggests that the contribution of this highly error-prone DNA pol is low in this experimental system.

In contrast, however, the incorporation of $8-\mathrm{OH}-$ dGTP by DNA pol $\eta$ may induce mutations in living human cells, since the mutagenicity of $8-\mathrm{OH}-\mathrm{dGTP}$ directly incorporated into cells was reduced significantly when the expression of DNA pol $\eta$ was disabled by siRNA (Satou et al., unpublished results).
Nucleotide Pool Sanitization Enzymes in E. coli

MutT is the gene product of the $E$. coli mutator gene, mutT (nudA). Disruption of the mutT gene led to an increased frequency of $\mathrm{A}: \mathrm{T} \rightarrow \mathrm{C}: \mathrm{G}$ mutations $(9,33)$. In 1992, Maki and Sekiguchi found that the MutT protein specifically hydrolyzed 8-OH-dGTP to form the corresponding monophosphate (Table 2) (12). This report highlighted the role of 'nucleotide pool sanitization' to prevent the mutagenesis induced by damaged DNA precursors. The facts that the accumulation of $8-\mathrm{OH}-$ Gua by the incorporation of 8-OH-dGTP contributed almost equally to the direct oxidation of $G$ bases in DNA (9), and that the A:T $\rightarrow C: G$ transversions occurred with high frequency in the $m u t T$ strain, indicate the importance of nucleotide pool sanitization as the first defense system against damaged DNA precursors. In agreement with this interpretation, exogenous 8-OHdGTP induced mutations more efficiently in an mutT strain than in the wt strain (34). This result constitutes the first direct evidence that the MutT protein suppresses mutations by 8-OH-dGTP in vivo. Recently, 8hydroxy 2'-deoxyguanosine 5'-diphosphate $(8-\mathrm{OH}-$ dGDP) was found to be another substrate for the MutT protein (35). Although the biological significance of this enzymatic activity is unknown, the authors of the paper suggested that 8-OH-dGTP and 8-OH-dGDP are interconvertible by the actions of nucleoside diphosphate kinase and nucleoside triphosphatase, which do not discriminate these damaged deoxyribonucleotides from the normal ones (36).

The E. coli Orf135 (NudG) protein is another MutTtype enzyme and contains the 'MutT signature/ phosphohydrolase module/Nudix box' (37-39). This protein catalyzes the hydrolysis of 2-OH-dATP, and somewhat less efficiently, 8-OH-dGTP (Table 2) (40). Exogenous 2-OH-dATP induced mutations more efficiently in an orf135 strain than in the wt strain (41), suggesting that the Orf135 protein catalyzes the hydrolysis of 2-OH-dATP in vivo. On the other hand, $8-\mathrm{OH}-$ dGTP induced mutations similarly in the orf135 and wt

Table 2. MutT-type nucleotide pool sanitization enzymes

\begin{tabular}{ll}
\hline \hline Proteins & Candidate substrates \\
\hline E. coli & \\
MutT & 8-OH-dGTP, 8-OH-dGDP \\
Orf17 & 8-OH-dATP, 2-OH-dATP, 8-OH-dGTP \\
& 8-OH-dADP, 2-OH-dADP, 8-OH-dGDP \\
Orf135 & 2-OH-dATP, 8-OH-dGTP \\
S. cerevisiae & \\
PCD1 & 8-OH-dGTP, 2-OH-dATP \\
Mammalian cells & \\
MTH1 & 8-OH-dGTP, 2-OH-dATP, 8-OH-dATP \\
MTH2 & 8-OH-dGTP \\
NUDT5 & 8-OH-dGDP \\
\hline
\end{tabular}


strains. This result suggests that the MutT protein, rather than the Orf 135 protein, primarily degrades 8OH-dGTP in E. coli. The spontaneous and $\mathrm{H}_{2} \mathrm{O}_{2}$-induced mutant frequencies were two- to three-fold higher in the orf135 strain than in the wt strain (41). Various mutations involving a $\mathrm{G}: \mathrm{C} \rightarrow \mathrm{T}: \mathrm{A}$ transversion, the same type of mutation induced by 2-OH-dATP, occurred more frequently in the orf135 strain than in the wt strain.

Orf135 proteins with substitutions at amino acid residues in the Mut $\mathrm{T}$ signature sequence were generated, and the in vitro enzymatic activities were measured (42). In addition, the mutant Orf135 proteins were each expressed in the orf135 strain, and the mutation frequency upon $\mathrm{H}_{2} \mathrm{O}_{2}$ treatment was examined (43). The in vivo mutation suppression abilities and the in vitro enzymatic activities were then compared. The expression of the enzymatically active Orf 135 mutants in the orf 135 strain tended to reduce the mutation frequency induced by $\mathrm{H}_{2} \mathrm{O}_{2}$ (43). This result suggests the importance of the phosphohydrolase activity in the suppression of mutations by the Orf135 protein. Mutant Orf135 proteins with substitutions at amino acid residues that are putatively involved in the base recognition of substrates were generated, and the in vitro enzymatic activities and the in vivo mutation suppression abilities were compared (44). A statistically significant correlation was found only between the $\mathrm{H}_{2} \mathrm{O}_{2}$-induced mutation frequencies and the 2-OH-dATPase activity (albeit partially). The results of these experiments suggest that the 2-OHdATPase activity of the Orf 135 protein contributes to the suppression of the ROS-induced mutagenesis derived from oxidized deoxyribonucleotide(s) in $E$. coli cells.

Another MutT-type enzyme, Orf17 (NudB), catalyzes the hydrolysis of 8-OH-dATP and, less efficiently, 8OH-dGTP and 2-OH-dATP (Table 2) (45). The Orf17 protein also catalyzes the hydrolysis of their diphosphate derivatives. Since the destruction of the orfl7 gene results in severe growth inhibition, plasmid DNA containing the gene in the antisense orientation, under an inducible promoter, was introduced into $E$. coli (46). Although a slightly increased mutation frequency was observed for spontaneous mutations, no clear phenotype was observed for $\mathrm{H}_{2} \mathrm{O}_{2}$ - and X-ray-induced mutations. Moreover, the introduction of 8-OH-dATP into the antisense-expressing cells did not induce mutations (Hori et al., unpublished results). Although it is possible that 8-OH-dATP itself is not mutagenic (28), the Orf17 protein may not contribute to the suppression of ROSinduced mutations. On the other hand, the overexpression of the Orf17 protein in mutT cells decreased the mutation frequency (46). This result suggests that the Orf17 protein could act as a backup protein for the MutT protein.
The RibA protein (GTP cyclohydrolase II), which is involved in riboflavin synthesis, catalyzes the hydrolysis of 8-OH-dGTP in vitro (47). The ribA gene reduced the increased level of mutation frequency in the $m u t T$ strain to almost the normal level, when the gene product was overproduced. In the mut $T$ background, the $\operatorname{rib} A$ cells showed higher spontaneous mutation frequencies, as compared with that of rib $A^{+}$cells. Thus, GTP cyclohydrolase II has the potential to protect genetic material from the untoward effects of ROS. Although the RibA protein is not a member of the Nudix superfamily, it could act as a backup protein for the MutT protein.

\section{Nucleotide Pool Sanitization Enzyme in Yeast}

Nunoshiba et al. found that the Saccharomyces cerevisiae PCD1 (YLR151c) protein, a member of the Nudix superfamily, catalyzes the hydrolysis of $8-\mathrm{OH}-$ dGTP and 2-OH-dATP (Table 2) (48). Expression of PCD1 suppressed the A:T $\rightarrow C: G$ transversion in the $E$. coli mutT strain. The disruption of the PCD1 gene in yeast caused a 14-fold increase in the frequency of spontaneous mutations, as compared to the wt strain. Thus, PCD1 has the ability to prevent spontaneous mutagenesis via sanitization of the nucleotide pool, and therefore, it may be the functional homologue of E. coli MutT in S. cerevisiae.

\section{Nucleotide Pool Sanitization Enzymes in Mam- malian Cells}

In mammalian cells, the MTH1 protein, a member of the MutT-type enzymes containing the MutT signature/phosphohydrolase module/Nudix box, hydrolyzes $8-O H-d G T P$ (Table 2) $(49,50)$. When the cDNA for human MTH1 was expressed in E. coli mutT mutant cells, the elevated level of spontaneous $A: T \rightarrow C: G$ mutations reverted to the normal level (51). This protein also catalyzes the hydrolysis of 2-OH-dATP and 8-OHdATP in vitro (52). Tsuzuki et al. reported that a greater number of tumors were spontaneously formed in the lungs, livers, and stomachs of MTH1-deficient mice, as compared with wt mice (53). Thus, the accumulation of 8-OH-dGTP and 2-OH-dATP in the nucleotide pool might induce mutations in tumor-related genes, thus enhancing tumorigenesis. Nakabeppu and collaborators generated mutant MTH1 proteins that lacked either the 8-OH-dGTPase or 2-OH-dATPase activity (54). Using these mutant MTH1 proteins, they revealed that the $\mathrm{H}_{2} \mathrm{O}_{2}$-induced cell dysfunction and death observed in MTH1-null mouse embryo fibroblasts were effectively suppressed by the expression of wt human MTH1, and that they were only partially suppressed by the expression of a mutant MTH1, defective in either the 8-OHdGTPase or 2-OH-dATPase activity (55). 2-OH-dATP synergistically enhanced the mutagenicity of $8-\mathrm{OH}-$ dGTP in in vitro DNA replication with an extract of hu- 
man cells (30). 2-OH-dATP suppressed the hydrolysis of 8 -OH-dGTP, suggesting that the inhibition of the MTH1(-like) protein plays a major role in the enhancement. These results highlight the importance of the specific hydrolysis of 8-OH-dGTP for the suppression of its induced mutation.

Another member of the mammalian MutT-type enzymes is the MTH2 protein. The protein obtained by the expression of the cloned mouse MTH2 cDNA catalyzes the hydrolysis of 8-OH-dGTP (56). Expression of the cDNA encoding MTH2 significantly reduced the elevated level of spontaneous mutation frequency in E. coli $m u t T$ cells. Thus, MTH 2 could act as a backup protein for the MTH1 protein.

The human Nudix type 5 (NUDT5) protein catalyzes the hydrolysis of 8-OH-dGDP to the monophosphate derivative (57). On the other hand, the hydrolysis of 8OH-dGTP is catalyzed by the NUDT5 protein only at very low levels. However, the increased frequency of spontaneous mutations in $E$. coli mut $T$ cells is decreased to normal levels when NUDT5 is expressed. This result suggests that the elimination of the damaged deoxyribonucleoside diphosphate from the nucleotide pool is important for the prevention of mutations. As described above, 8-OH-dGTP and 8-OH-dGDP are interconvertible in cells, and the removal of either deoxyribonucleotide may contribute to mutation prevention to similar degrees.

The reports described above indicate that the nucleotide pool sanitization enzymes contribute to the suppression of mutations, and that damaged DNA precursors are potentially endogenous mutagens. The fact that $E$. coli, yeast, and mammalian cells possess enzyme(s) with 2-OH-dATPase activity indicates that 2-OH-dATP is an important oxidized DNA precursor.

\section{Roles of DNA Repair Proteins}

As described above, the nucleotide pool sanitization enzymes act as the first defense against the mutagenesis by damaged DNA precursors. Alternatively, DNA repair enzymes may prevent the mutagenesis by the oxidized deoxyribonucleotides after their incorporation into DNA. We recently examined this possibility, using $E$. coli strains deficient in a gene related to DNA repair. Our data suggested that endonuclease III (Nth) functions as the second defense against 8-OH-dGTP (58). In contrast, UvrA and UvrB enhanced the mutations induced by oxidized deoxyribonucleotides by unknown mechanism(s) (59). The roles of DNA repair proteins in the mutagenesis by damaged DNA precursors should be elucidated in detail.

\section{Conclusions}

Damaged DNA precursors formed in the nucleotide pool by the action of ROS contribute to mutation induc- tion. The nucleotide pool sanitization enzymes function as the first defense against the damaged DNA precursors. A through understanding the roles of specialized DNA pols and DNA repair proteins is necessary to gain a clear view of the effects of oxidized DNA precursors.

Acknowledgements: The author wishes to thank the collaborators who participated in the experiments described in this paper, especially Prof. Hiroshi Kasai, of the University of Occupational and Environmental Health, and Prof. Hideyoshi Harashima, of Hokkaido University. Work in our laboratory was supported in part by Grants-in-Aid from the Japan Society for the Promotion of Science, and the Ministry of Education, Culture, Sports, Science and Technology of Japan.

\section{References}

1 Ames BN. Dietary carcinogens and anticarcinogens. Science. 1983; 221: 1256-64.

2 Ames BN, Gold LS. Endogenous mutagens and the causes of aging and cancer. Mutat Res. 1991; 250: 3-16.

3 Henle ES, Linn S. Formation, prevention, and repair of DNA damage by iron/hydrogen peroxide. J Biol Chem. 1997; 272: 19095-8.

4 Hiraku Y, Murata M, Kawanishi S. Role of oxidative DNA damage in dietary carcinogenesis. Genes Environment. 2006; 28: 127-40.

5 Kamiya H. Mutagenic potentials of damaged nucleic acids produced by reactive oxygen/nitrogen species: Approaches using synthetic oligonucleotides and nucleotides. Nucleic Acids Res. 2003; 31: 517-31.

6 Harman D. The aging process. Proc Natl Acad Sci USA. 1981; 78: 7124-8.

7 Sekiguchi M, Tsuzuki T. Oxidative nucleotide damage: consequences and prevention. Oncogene. 2002; 21: 8895-904.

8 Kamiya H, Kasai H. Formation of 2-hydroxydeoxyadenosine triphosphate, an oxidatively damaged nucleotide, and its incorporation by DNA polymerases. J Biol Chem. 1995; 270: 19446-50.

9 Tajiri T, Maki H, Sekiguchi M. Functional cooperation of MutT, MutM and MutY proteins in preventing mutations caused by spontaneous oxidation of guanine nucleotide in Escherichia coli. Mutat Res. 1995; 336: 257-67.

10 Nunoshiba T, Watanabe T, Nakabeppu Y, Yamamoto K. Mutagenic target for hydroxyl radicals generated in Escherichia coli mutant deficient in $\mathrm{Mn}$ - and Fe-superoxide dismutases and Fur, a repressor for iron-uptake systems. DNA Repair. 2002; 1: 411-8.

11 Murata-Kamiya N, Kamiya H, Muraoka M, Kaji H, Kasai H. Comparison of oxidation products from DNA components by $\gamma$-irradiation and Fenton-type reactions. J Radiat Res. 1997; 38: 121-31.

12 Maki H, Sekiguchi M. MutT protein specifically hydrolyses a potent mutagenic substrate for DNA synthesis. Nature. 1992; 355: 273-5.

13 Purmal AA, Kow YW, Wallace SS. 5-Hydroxypymidine deoxynucleoside triphosphates are more efficiently incor- 
porated into DNA by exonuclease-free Klenow fragment than 8-oxopurine deoxynucleoside triphosphates. Nucleic Acids Res. 1994; 22: 3930-5.

14 Einolf HJ, Schnetz-Boutaud N, Guengerich FP. Steadystate and pre-steady-state kinetic analysis of 8-oxo-7,8-dihydroguanosine triphosphate incorporation and extension by replicative and repair DNA polymerases. Biochemistry. 1998; 37: 13300-12.

15 Miller H, Prasad R, Wilson SH, Johnson F, Grollman AP. 8-oxodGTP incorporation by DNA polymerase $\beta$ is modified by active-site residue Asn279. Biochemistry. 2000; 39: 1029-33.

16 Einolf HJ, Guengerich FP. Fidelity of nucleotide insertion at 8-oxo-7,8-dihydroguanine by mammalian DNA polymerase $\delta$. Steady-state and pre-steady-state kinetic analysis. J Biol Chem. 2001; 276: 3764-71.

17 Shimizu M, Gruz P, Kamiya H, Kim S-R, Pisani FM, Masutani C, Kanke Y, Harashima H, Hanaoka F, Nohmi T. Erroneous incorporation of oxidized DNA precursors by Y-family DNA polymerases. EMBO Rep. 2003; 4: 269-73.

18 Yamada M, Nunoshiba T, Shimizu M, Gruz P, Kamiya $\mathrm{H}$, Harashima $\mathrm{H}$, Nohmi $\mathrm{T}$. Involvement of Y-family DNA polymerases in mutagenesis caused by oxidized nucleotides in Escherichia coli. J Bacteriol. 2006; 188: 4992-5.

19 Shimizu M, Gruz P, Kamiya H, Masutani C, Xu Y, Usui Y, Sugiyama H, Harashima H, Hanaoka F, Nohmi T. Efficient and erroneous incorporation of oxidized DNA precursors by human DNA polymerase $\eta$. Biochemistry. 2007; 46: 5515-22.

20 Cheng KC, Cahill DS, Kasai H, Nishimura S, Loeb LA. 8-Hydroxyguanine, an abundant form of oxidative DNA damage, causes $\mathrm{G} \rightarrow \mathrm{T}$ and $\mathrm{A} \rightarrow \mathrm{C}$ substitutions. J Biol Chem. 1992; 267: 166-72.

21 Pavlov YI, Minnick DT, Izuta S, Kunkel TA. DNA replication fidelity with 8-oxodeoxyguanosine triphosphate. Biochemistry. 1994; 33: 4695-701.

22 Kamiya H, Kasai H. 2-Hydroxy-dATP is incorporated opposite G by Escherichia coli DNA polymerase III resulting in high mutagenicity. Nucleic Acids Res. 2000; 28: 1640-6.

23 Kamiya H, Maki H, Kasai H. Two DNA Polymerases of Escherichia coli display distinct misinsertion specificities for 2-hydroxy-dATP during DNA synthesis. Biochemistry. 2000; 39: 9508-13.

24 Kamiya H, Ueda T, Ohgi T, Matsukage A, Kasai H. Misincorporation of dAMP opposite 2-hydroxyadenine, an oxidative form of adenine. Nucleic Acids Res. 1995; 23: 761-6.

25 Kamiya H, Kasai H. Effects of sequence contexts on misincorporation of nucleotides opposite 2-hydroxyadenine. FEBS Lett. 1996; 391: 113-6.

26 Inoue $\mathrm{M}$, Kamiya $\mathrm{H}$, Fujikawa $\mathrm{K}$, Ootsuyama $\mathrm{Y}$, Murata-Kamiya N, Osaki T, Yasumoto K, Kasai H. Induction of chromosomal gene mutations in Escherichia coli by direct incorporation of oxidatively damaged nucleotides. J Biol Chem. 1998; 273: 11069-74.

27 Fujikawa K, Kamiya H, Kasai H. The mutations induced by oxidatively damaged nucleotides, 5-formyl-dUTP and
5-hydroxy-dCTP, in Escherichia coli. Nucleic Acids Res. 1998; 26: 4582-7.

28 Hori $\mathrm{M}$, Ishiguro $\mathrm{C}$, Harashima $\mathrm{H}$, Kamiya $\mathrm{H}$. In vivo mutagenicities of damaged nucleotides produced by nitric oxide and ionizing radiation. Biol Pharm Bull. 2005; 28: 520-2.

29 Satou K, Harashima H, Kamiya H. Mutagenic effects of 2-hydroxy-dATP on replication in a HeLa extract: Induction of substitution and deletion mutations. Nucleic Acids Res. 2003; 31: 2570-5.

30 Satou K, Kasai H, Masutani C, Hanaoka F, Harashima H, Kamiya H. 2-Hydroxy-2'-deoxyadenosine 5'triphosphate enhances $\mathrm{A} \cdot \mathrm{T} \rightarrow \mathrm{C} \cdot \mathrm{G}$ mutations caused by 8-hydroxy-2'-deoxyguanosine 5'-triphosphate by suppressing its degradation upon replication in a HeLa extract. Biochemistry. 2007; 46: 6639-46.

31 Satou K, Kawai K, Kasai H, Harashima H, Kamiya H. Mutagenic effects of 8-hydroxy-dGTP in live mammalian cells. Free Rad Biol Med. 2007; 42: 1552-60.

32 Satou K, Yamada M, Nohmi T, Harashima H, Kamiya H. Mutagenesis induced by oxidized DNA precursors: roles of Y-family DNA polymerases in Escherichia coli. Chem Res Toxicol. 2005; 18: 1271-8.

33 Yanofsky C, Cox EC, Horn V. The unusual mutagenic specificity of an E. coli mutator gene. Proc Natl Acad Sci USA. 1966; 55: 274-81.

34 Kamiya $H$, Ishiguro $C$, Harashima $H$. Increased $\mathrm{A}: \mathrm{T} \rightarrow \mathrm{C}: \mathrm{G}$ mutations in the mut $T$ strain upon 8-hydroxydGTP treatment: Direct evidence for MutT involvement in the prevention of mutations by oxidized dGTP. J Biochem. 2004; 136: 359-62.

35 Ito R, Hayakawa H, Sekiguchi M, Ishibashi T. Multiple enzyme activities of Escherichia coli MutT protein for sanitization of DNA and RNA precursor pools. Biochemistry. 2005; 44: 6670-4.

36 Hayakawa H, Taketomi A, Sakumi K, Kuwano M, Sekiguchi,M. Generation and elimination of 8-oxo-7,8dihydro-2'-deoxyguanosine 5'-triphosphate, a mutagenic substrate for DNA synthesis, in human cells. Biochemistry. 1995; 34: 89-95.

37 Nakabeppu Y. Molecular genetics and structural biology of human MutT homolog, MTH1. Mutat Res. 2001; 477: 59-70.

38 Bessman MJ, Frick DN, O'Handley SF. The MutT proteins or "Nudix"' hydrolases, a family of versatile, widely distributed, "housecleaning", enzymes. J Biol Chem. 1996; 271: 25059-62.

39 McLennan AG. The Nudix hydrolase superfamily. Cell Mol Life Sci. 2006; 63: 123-43.

40 Kamiya H, Murata-Kamiya N, Iida E, Harashima H. Hydrolysis of oxidized nucleotides by the Escherichia coli Orf135 protein. Biochem Biophys Res Commun. 2001; 288: 499-502.

41 Kamiya H, Iida E, Murata-Kamiya N, Yamamoto Y, Miki T, Harashima H. Suppression of spontaneous and hydrogen peroxide-induced mutations by a MutT-type nucleotide pool sanitization enzyme, the Escherichia coli Orf135 protein. Genes Cells. 2003; 8: 941-50.

42 Kamiya H, Iida E, Harashima H. Important amino acids in the phosphohydrolase module of Escherichia coli 
Orf135. Biochem Biophys Res Commun. 2004; 323: 1063-8.

43 H. Kamiya, E. Iida, and H. Harashima: Correlation between the phosphohydrolase activity of the Escherichia coli Orf135 (NudG) protein and mutation suppression. Genes Environment. 2007; 29: 63-6.

44 Iida E, Satou K, Mishima M, Kojima C, Harashima H, Kamiya H. Amino acid residues involved in substrate recognition of the Escherichia coli Orf135 protein. Biochemistry. 2005; 44: 5683-9.

45 Hori M, Fujikawa K, Kasai H, Harashima H, Kamiya H. Dual hydrolysis of diphosphate and triphosphate derivatives of oxidized deoxyadenosine by Orf17 (NtpA), a MutT-type enzyme. DNA Repair. 2005; 4: 33-9.

46 Hori M, Asanuma T, Inanami O, Kuwabara M, Harashima H, Kamiya $\mathrm{H}$. Effects of overexpression and antisense RNA expression of Orf17, a MutT-type enzyme. Biol Pharm Bull. 2006; 29: 1087-91.

47 Kobayashi M, Ohara-Nemoto Y, Kaneko M, Hayakawa H, Sekiguchi M, Yamamoto K. Potential of Escherichia coli GTP cyclohydrolase II for hydrolyzing 8-oxo-dGTP, a mutagenic substrate for DNA synthesis. J Biol Chem. 1998; 273: 26394-9.

48 Nunoshiba T, Ishida R, Sasaki M, Iwai S, Nakabeppu Y, Yamamoto K. A novel nudix hydrolase for oxidized purine nucleoside triphosphates encoded by ORFYLR151c (PCD1 gene) in Saccharomyces cerevisiae. Nucleic Acids Res. 2004; 32: 5339-48.

49 Mo JY, Maki H, Sekiguchi M. Hydrolytic elimination of a mutagenic nucleotide, 8-oxodGTP, by human 18kilodalton protein: sanitization of nucleotide pool. Proc Natl Acad Sci USA. 1992; 89: 11021-5.

50 Sakumi K, Furuichi M, Tsuzuki T, Kakuma T, Kawabata S, Maki H, Sekiguchi M. Cloning and expression of cDNA for a human enzyme that hydrolyzes 8-oxo-dGTP, a mutagenic substrate for DNA synthesis. J Biol Chem. 1993; 268: 23524-30.

51 Furuichi M, Yoshida MC, Oda H, Tajiri T, Nakabeppu Y, Tsuzuki T, Sekiguchi M. Genomic structure and chromosome location of the human mut homologue gene MTH1 encoding 8-oxo-dGTPase for prevention of A:T to C:G transversion. Genomics. 1994; 24: 485-90.

52 Fujikawa K, Kamiya H, Yakushiji H, Fujii Y, Nakabeppu Y, Kasai H. The oxidized forms of dATP are substrates for the human MutT homologue, the hMTH1 protein. J Biol Chem. 1999; 274: 18201-5.

53 Tsuzuki T, Egashira A, Igarashi H, Iwakuma T, Nakatsuru Y, Tominaga Y, Kawate H, Nakao K, Nakamura K, Ide F, Kura S, Nakabeppu Y, Katsuki M, T. Ishikawa M. Sekiguchi M. Spontaneous tumorigenesis in mice defective in the MTH1 gene encoding 8-oxo-dGTPase. Proc Natl Acad Sci USA. 2001; 98: 11456-61.

54 Sakai Y, Furuichi M, Takahashi M, Mishima M, Iwai S, Shirakawa M, Nakabeppu Y. A molecular basis for the selective recognition of 2-hydroxy-dATP and 8-oxodGTP by human MTH1. J Biol Chem. 2002; 277: 8579-87.

55 Yoshimura D, Sakumi K, Ohno M, Sakai Y, Furuichi M, Iwai S, Nakabeppu Y. An oxidized purine nucleoside triphosphatase, MTH1, suppresses cell death caused by oxidative stress. J Biol Chem. 2003; 278: 37965-73.

56 Cai JP, Ishibashi T, Takagi Y, Hayakawa H, Sekiguchi M. Mouse MTH2 protein which prevents mutations caused by 8 -oxoguanine nucleotides. Biochem Biophys Res Commun. 2003; 305: 1073-7.

57 Ishibashi T, Hayakawa H, Sekiguchi M. A novel mechanism for preventing mutations caused by oxidation of guanine nucleotides. EMBO Rep. 2003; 4: 479-83.

58 Suzuki T, Yamamoto K, Harashima H, Kamiya H. Base excision repair enzyme endonuclease III suppresses mutagenesis caused by 8-hydroxy-dGTP. DNA Repair. in press.

59 Hori M, Ishiguro C, Suzuki T, Nakagawa N, Nunoshiba T, Kuramitsu S, Yamamoto K, Kasai H, Harashima H, Kamiya H. UvrA and UvrB enhance mutations induced by oxidized deoxyribonucleotides. DNA Repair. in press.

60 Sepiol J, Kazimierczuk Z, Shugar D. Tautomerism of isoguanosine and solvent-induced keto-enol equilibrium. Z Naturforsch. 1976; 31C: 361-70.

61 Seela J, Wei C, Kazimierczuk Z. Substituent reactivity and tautomerism of isoguanosine and related nucleosides. Helv Chim Acta. 1995; 78: 1843-54. 